
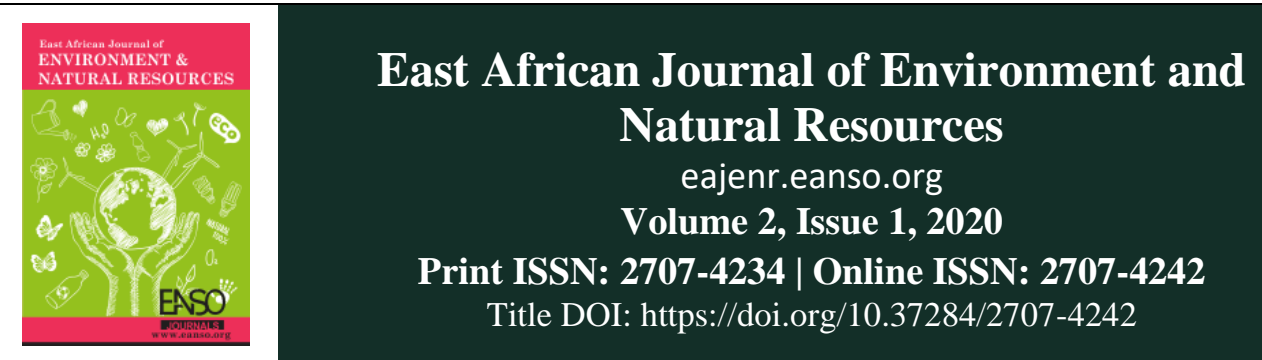

Original Article

\title{
The Woody Plant Species Diversity, Composition and Dominance of Mahungu Green Belt Forest Reserve (MGBFR) in Dodoma City, Central Tanzania
}

\author{
Canisius John Kayombo ${ }^{1 *}$, Chrispinus D. K. Rubanza ${ }^{2}$, \\ Richard Alphonce Giliba ${ }^{3} \&$ Almas Kashindye \\ ${ }^{1}$ Department of Botany, College of Natural and Applied Sciences, University of Dar es Salaam, Tanzania \\ ${ }^{2}$ College of Natural and Applied Science, University of Dodoma \\ ${ }^{3}$ Forestry Training Institute, Olmotonyi. P. O. Box 35091, Dar es Salaam, Tanzania. \\ *Author for Correspondence email: kayombo33@yahoo.co.uk or kayombocanisius@ gmail.com
}

Article DOI: https://doi.org/10.37284/eajenr.2.1.125

Article history:

Received: 22 Feb 2019

Accepted: 14 Mar 2019

Published: 26 Mar 2020

Keywords:

Trees, Shrubs, Lianas, Diversity, Dominance, Evenness, Mahungu Green Belt Forest Reserve, Dodoma.

\begin{abstract}
Plant species diversity, composition and dominance are important entities in understanding vegetation types. The wood plant species include; trees, shrubs, and woody climbers (lianas/vines). The study was conducted at Mahungu Green Belt Forest Reserve (MGBFR) in 2015 to investigate the woody plant species diversity, composition, and dominance. Systematic random sampling was applied whereby a total of 36 plots of $2500 \mathrm{~m}^{2}$ were set in the seven (7) transects at an interval of $400 \mathrm{~m}$. Woody plant species were identified for their botanical nomenclature, determined for their abundance. GPS was applied to locate plots, aligning transects and recording coordinates for plot site and map production. $100 \mathrm{~m}$ tape was used to set the plots. H' and ID were applied for species diversity and dominance. A total of 129 woody plant species were identified belonging to 38 families and 89 genera. The $\mathrm{H}$ ' ranged from 0.1831 \pm 0.0021 , with an overall total of 4.271 while ID ranged from $0.004657 \pm$ 0.000015 with a total of 0.02079 an implication of high wood plant diversity, as the higher the $\mathrm{H}^{\prime}$, and the lower the ID the higher the diversity. MGBFR consists of high woody plant species diversity. Further study should be done to assess all plant forms of MGBFR, education provision to community, establishment of ecotourism industry to sustain the forest reserve.
\end{abstract}




\section{APA CITATION}

Kayombo, C., Rubanza, C., Giliba, R., \& Kashindye, A. (2020). The Woody Plant Species Diversity, Composition and Dominance of Mahungu Green Belt Forest Reserve (MGBFR) in Dodoma City, Central Tanzania. East African Journal of Environment and Natural Resources, 2(1), 1-13. https://doi.org/10.37284/eajenr.2.1.125

\section{CHICAGO CITATION}

Kayombo, Canisius, Chrispinus Rubanza, Richard Giliba, and Almas Kashindye. 2020. "The Woody Plant Species Diversity, Composition and Dominance of Mahungu Green Belt Forest Reserve (MGBFR) in Dodoma City, Central Tanzania”. East African Journal of Environment and Natural Resources 2 (1), 1-13. https://doi.org/10.37284/eajenr.2.1.125.

\section{HARVARD CITATION}

Kayombo, C., Rubanza, C., Giliba, R. and Kashindye, A. (2020) "The Woody Plant Species Diversity, Composition and Dominance of Mahungu Green Belt Forest Reserve (MGBFR) in Dodoma City, Central Tanzania", East African Journal of Environment and Natural Resources, 2(1), pp. 1-13. doi: 10.37284/eajenr.2.1.125.

\section{IEEE CITATION}

C. Kayombo, C. Rubanza, R. Giliba, and A. Kashindye, "The Woody Plant Species Diversity, Composition and Dominance of Mahungu Green Belt Forest Reserve (MGBFR) in Dodoma City, Central Tanzania”, EAJENR, vol. 2, no. 1, pp. 1-13, Mar. 2020.

\section{MLA CITATION}

Kayombo, Canisius, Chrispinus Rubanza, Richard Giliba, and Almas Kashindye. "The Woody Plant Species Diversity, Composition and Dominance of Mahungu Green Belt Forest Reserve (MGBFR) in Dodoma City, Central Tanzania". East African Journal of Environment and Natural Resources, Vol. 2, no. 1, Mar. 2020, pp. 1-13, doi:10.37284/eajenr.2.1.125.

\section{INTRODUCTION}

The floristic composition and diversity of a certain area depends on the time and the habitat types in which data were collected (Evangelista et al., 2016). Green belt is an area of vegetation or a mass plantation of pollutant-tolerant trees around a city, on which building is restricted for mitigating air pollution by intercepting, filtering and absorbing pollutants in a sustainable manner (Missanjo et al., 2015; UNEP, 2007)). According to UNEP (2007) and Da Silva (2009), open spaces are refugees and nature reserves set aside for the sake of protecting species other than human beings. Malimbwi (2004) and Kupnick (2001) stated that the diversity of plant life is an essential factor underpinning of most of our terrestrial ecosystems. The woody plant species including shrubs, lianas and trees that provide construction materials, energy source, carbon dioxide sinks, protection of erosion, windbreak, rainfall regulation, and food and many other useful goods and services (Bein et al., 1996; Naughton, 2007; Malmer \& Nyberg, 2008; Mugasha et al., 2010). Trees are woody plants that are the largest and most prominent of all plant forms of the world plants usually with a single stem called a trunk and when more than a single stem they are differentiated from other woody plant forms by their height and diameter which is always the largest of all other woody plants forms. Shrubs are the woody plant species that are lower in size than the typical trees, usually less than $6 \mathrm{~m}$ tall, they bear slender and multi-stems. Woody climbers are also called liana are climbing woody plants or woody leaning plants (Beetnje, 1994). Biological diversity often has immediate significance to traditional societies whose people live close to the land and water (Primack, 2002).

Worldwide the land is covered by a variety of flora of which the prominently seen are the woody plants (Moore et al., 1995) and humans have relied on the plants for survival and pleasure (Owen-Smith \& Cooper, 1987). The dependence on plants persists and almost everything we do is influenced either directly or indirectly by plants (Tunholi et al., 2013). The world uses plants to make clothes, strings, ropes, resin, lumber, musical instruments, sports equipment, furniture, fabrics, cardboards, source of energy and these are only a small part of their importance to us (Thijs, 2014). In the tropics alone it has been estimated that 2,500,030,000 species are in use for various purposes (Heywood, 1992). Green belt forest reserves represent a potential approach towards the enhanced supply of ecosystem goods and services in many urban and peri-urban areas in the tropics including Dodoma Municipality (URT, 2007).

Tanzania with an area of 945,000 $\mathrm{km}^{2}$ has high plant species diversity (Ruffo et al., 2002). There 
are over 9,000 plant species of higher plants in Tanzania, many of which are so-called endemic species, meaning that they are only found in Tanzania. (Ruffo et al., 2002; Temu and Nsolomo, 2000). The threatened woodland plant species include Brachystegia spiciformis, B. microphylla, B. boehmii, Isoberlinia angolensis, Pterocarpus angolensis, $P$. tinctorius, and Pericopsis angolensis (Baldus \& Siege, 2003). According to the National Beekeeping Programme (URT, 2004), Tanzania has about 38.8 million ha of forests that make up $44 \%$ of the total land on the mainland. The forests also support wildlife, as well as provide regulation of temperature and rainfall, prevention of landslides (Kupnick, 2001), however little information exists on their diversity, composition and dominance of plant species in the forests.

According to Polhill (1988), botanical assessment has been proved to provide database of the localities of plants. The world accommodates enormous plant species diversity with a variety of values to both human beings and wildlife (Sapieha, 2008). The African continent contains high plant species diversity not well explored (Geldenhuys, 2013. The rich plant species of Tanzania have been surveyed at a very general level by botanist such as Ruffo et al. (2002) who explored the food plants of Tanzania, while many specific small areas have not been studied yet. Central Tanzania in which Dodoma region is situated comprises of high diversity of native woody plant species including Acacia tortilis, A. benthamii, A. mellifera, A. polyacantha, A. senegal, Commiphora spp., Maerua decumbens, Albizia tanganyikensis, A. petersiana, Lonchocarpus eriocalyx, Combretum spp., Brachystegia spiciformis, Julbernardia globiflora, Sclerocarrya birrea, Markhamia acuminata, and Curroria vulubilis beautifying the environment.

The Capital Development Authority Plan (URT, 1976) highlighted the green belt forest reserves including Chimwaga, Mbwanga, Mlimwa, Kige, Ihumwa and Mahungu as among important areas for recreational purposes, firewood supply and soil erosion protection function. However, scant information exists on plant species diversity, composition and dominance. This study aimed to investigate the woody plant species diversity, composition and dominance of MGBFR in Dodoma Municipality. Mahungu GBFR is among three remaining green belt forest patches after the change of land use from conservation of vegetation to settlement. The other outstanding forest patches included Chimwaga and Hombolo. MGBFR as a part and parcel of Dodoma municipality with high plant species diversity was established by CDA in 1973 so as to carter for firewood, recreational, windbreak and climate regulation (URT, 1973), however, inadequately has been done to investigate the plant species diversity, composition and dominance. It was hypothesized that there were significant differences in plant species diversity and dominance within the woody plant categories but significantly unevenly distributed. The associated research questions focused on the woody plant species diversity, composition and dominance.

\section{MATERIAL AND METHODS}

\section{Description of Study Area}

MGBFR is situated $10 \mathrm{~km}$ west of Dodoma Municipality Centre along the road to Bahi district (Figure 1). According to the CDA (URT, 2007), the Mahungu is positioned in the Dodoma Municipality woodland plain. The northern end of the forest reserve is situated at $6^{0} 23^{\prime} 5^{\prime \prime} \mathrm{S}$ and $35^{\circ} 45^{\mathrm{I}} 42^{\prime \prime} \mathrm{E}$, continuing to the south at $6^{0} 18^{\text {II }} 7^{\prime \prime} \mathrm{S}$ and $35^{\circ} 48^{\mathrm{I}}$ $9^{\mathrm{II}} \mathrm{E}$, also, $6^{0} 15^{\prime} 07^{\prime \prime} \mathrm{S}$ and $6^{0} 51^{\prime} 2^{\prime \prime} \mathrm{E}$ to the west and $6^{0} 08^{\prime} 33^{\prime \prime} \mathrm{S}$ and $35^{\circ} 40^{\prime} 08^{\prime \prime} \mathrm{E}$ to the eastern end of the forest reserve (Garmin GPS). The altitude ranges from 1141 metres for the lowest, while the highest undulating peak is $1380 \mathrm{~m}$ above sea level (Garmin GPS). MGBFR borders the three villages which are Nala in the northern and western side, and Zuzu Village in the southern side of the forest, both being in Nala ward. In the eastern side, the forest reserve borders the Mbwanga Village which is in Kizota Ward (Figure 1). 
Figure 1: A Map of Mahungu Green Belt Forest Reserve (MGBFR)

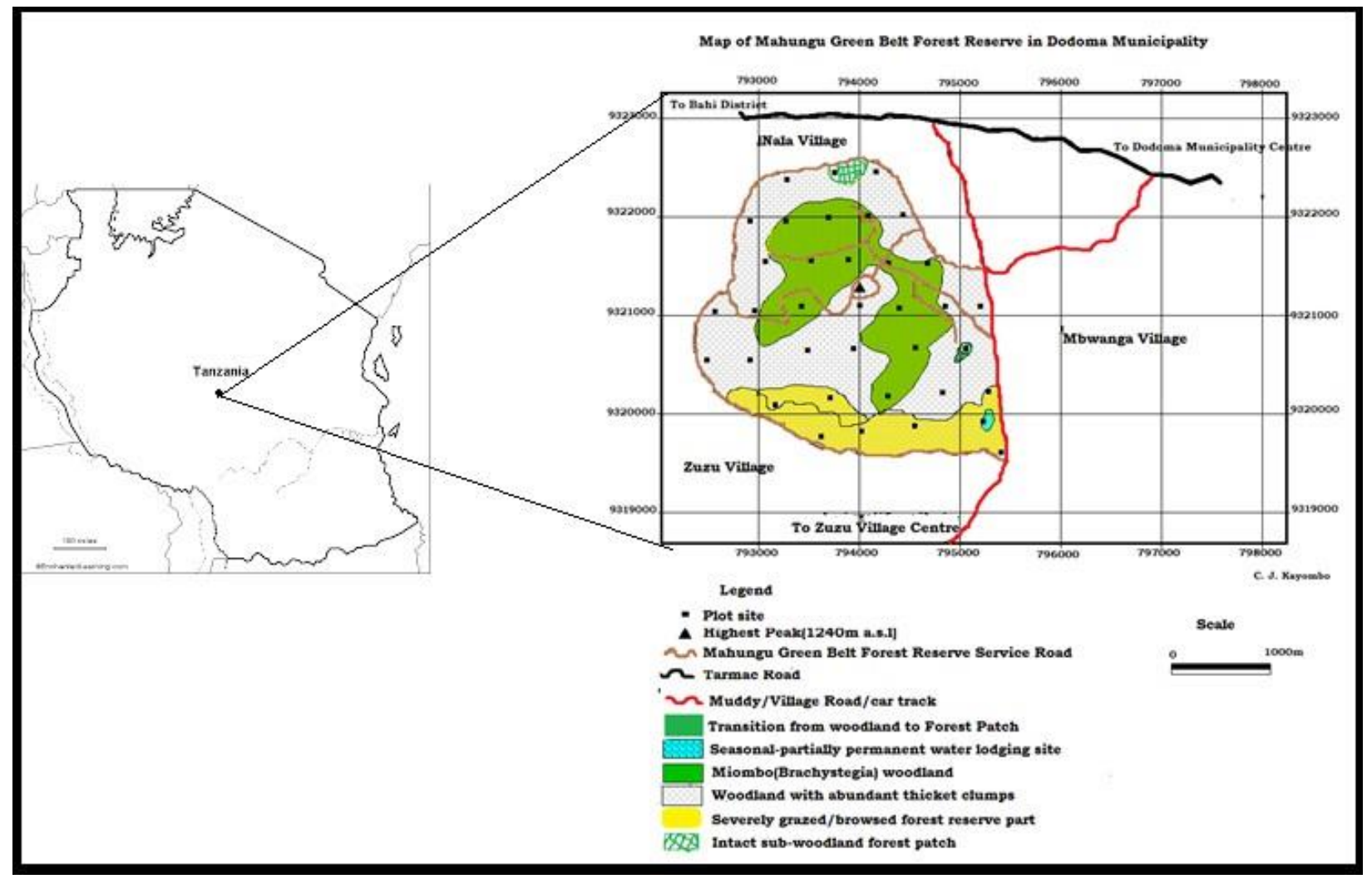

Source: Field survey, 2015.

\section{Vegetation and Climate of MGBFR}

The MGBFR being in the Dodoma region is within the natural plains marked by woodland patches, open grassland with little or no tree or bush cover. The types of ground cover of Dodoma are wooded grassland and bushes with thickets (URT, 2014). The bush tends to be leafless and dry in the dry season, but springs to luxuriant life during the rains when the whole countryside turns a brilliant green. Woodlands form the remainder of the area, with the heaviest concentrations on the hills of the CDA (URT, 2014). The vegetation of MGFR is dry savanna shrub-thicket land with scattered trees and grassland patches interrupted with trees and shrubs (Plate 1). The common plant species include Bussea massaiensis, Commiphora coerulea, C. ugogensis, C. africana, Acacia tortilis, A. senegal, Maerua decumbens, Combretum apiculatum, Grewia forbesii, Brachystegia spiciformis, Sclerocarrya birrea, Julbernardia globiflora, Delonix elata, Markhamia acuminate, Euphorbia candelabrum, and Terminalia sericea as indigenous taxa, mixed with exotics to include Peltophorum pterocarpum and Tamarindus indica. 
East African Journal of Environment and Natural Resources, Volume 2, Issue 1, 2020

Article DOI: https://doi.org/10.37284/eajenr.2.1.125

Plate 1: Woodland vegetation of MGBFR

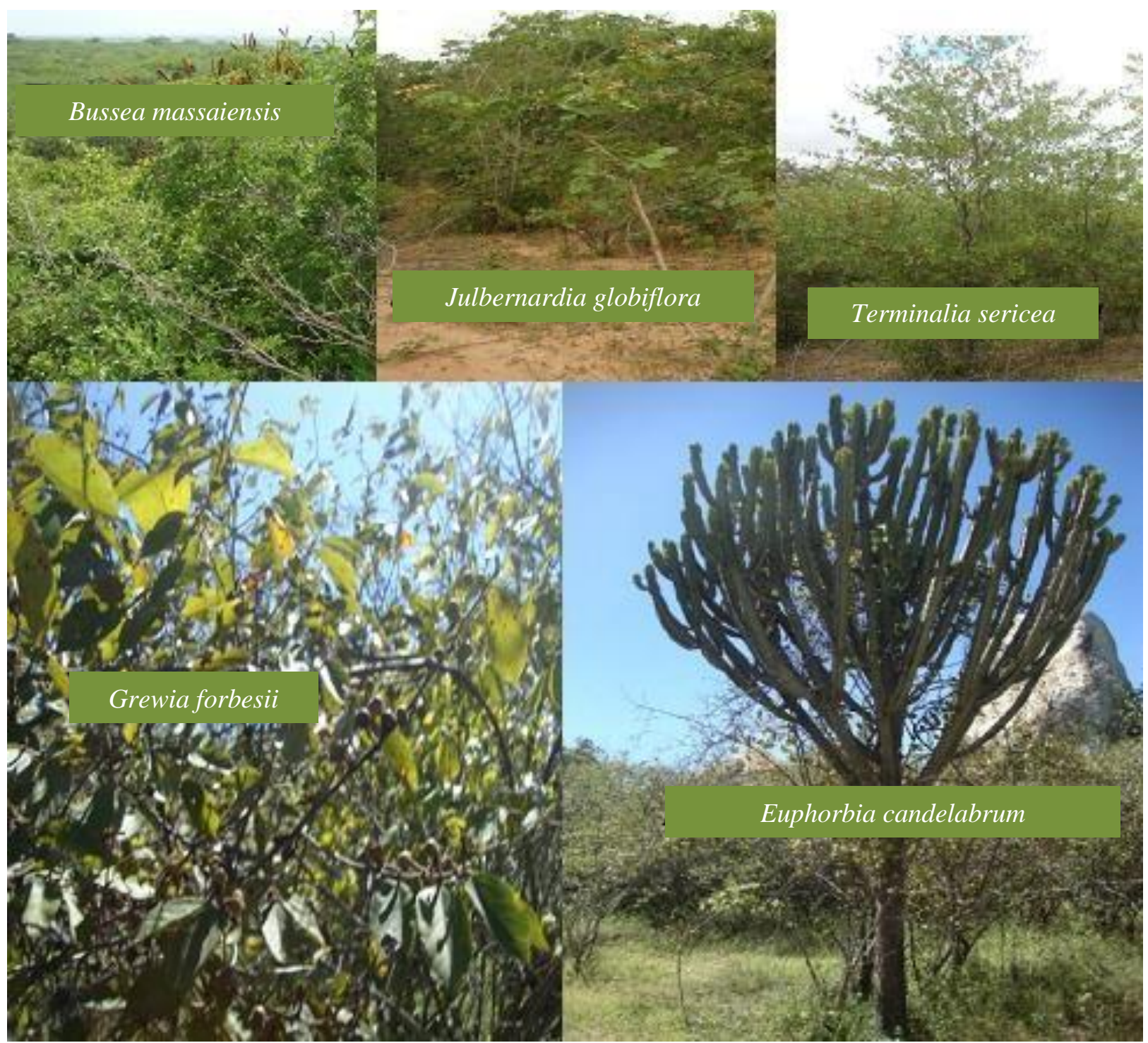

\section{Climate of MGBFR}

MGBFR being in Dodoma region has a dry savanna type of climate, which is characterized by a long dry season lasting between late April to early December and a short single wet season during the remaining months. The region lies in a rain shadow behind the mountains area of Dodoma in the eastern side (United Republic of Tanzania, 2002). The temperature in the region varies according to altitude but generally the average maximum and minimum for October to December are $31{ }^{\circ} \mathrm{C}$ and $18{ }^{\circ} \mathrm{C}$ respectively. The corresponding figures for the cool dry season of June-August are $27^{\circ} \mathrm{C}$ to 28 ${ }^{\circ} \mathrm{C}$ and $10{ }^{\circ} \mathrm{C}$ to $11{ }^{\circ} \mathrm{C}$ (degree centigrade) (URT,
2002). The average rainfall for Dodoma town is 570 $\mathrm{mm}$, and about $85 \%$ of this fall in four months between December and March. Rainfall is somewhat higher in the more agriculturally productive parts of Mpwapwa and Kondoa districts. Rainfall in Dodoma region is not only low but it is rather unpredictable in frequency and amount, particularly in the month of January in which most crops are generally sown (URT, 2002).

\section{Fauna}

The Forest Reserve accommodates a variety of wild animals such as Mongoose, dik dik, spotted hyena (Crocuta crocuta), hares (Lepus microtis), snakes 
such as Puff adder (Bitis arietans), Cobra (Naja naja), a variety of insects, birds including Franklin (Franklin alatamaha).

\section{Sampling Technique}

Systematic random sampling was employed for data collection. This method provides a chance for any element to be included during the study (Agresti \& Finlay, 2008). The first plot was set randomly at a distance between $50 \mathrm{~m}$ to $100 \mathrm{~m}$ from the forest edge, trailed systematically at an interval of $400 \mathrm{~m}$. Agresti and Finlay (2008) stated that the systematic random is a probabilistic sampling which is applied to avoid the edge effect. However, this method is useful in the mostly close to homogenous type of vegetation. The observed woody plant species were recorded for their scientific names and determined for their occurrence and plant specimens were collected and shipped to the National Herbarium of Tanzania (NHT) and Forestry Training Institute (FTOH) for identification. Sampling unit was a rectangular plot of $50 \mathrm{~m} \times 50 \mathrm{~m}\left[2500 \mathrm{~m}^{2}\right]$ as per Modified Whittaker (Stohlgren et a., 1995) consisting $5 \times 5 \mathrm{~m}$ [25 $\mathrm{m}^{2}$ ] subplots for evaluating the shrubs. This was a basic unit from which the researcher wishes to extract data shall be determined (Sarma, 2006). This entails the set of items or individuals selected from a larger aggregate or population about which the research wishes quantitative information (Sarma, 2006). The parameters of interest were the woody plant species, as variables to be investigated (Sarma, 2006). The sample size was 36 calculated from coefficient of variation formula;

$n=\frac{C V^{2} * t^{2}}{E^{e}}$ Where $\mathrm{CV}=$ coefficient variation; $\mathrm{t}$ (at $5 \%)=$ student $\mathrm{t}$ test $\mathrm{E}=$ allowable error

\section{Data Analysis}

\section{Shannon Wiener Diversity Index $\left(H^{\prime}\right)$}

Data were analyzed using Shannon wiener for woody plant and Simpson indices for species richness and dominance (Kent \&Coker, 1992; Sarma, 2006). Shannon Wiener $\left(\mathrm{H}^{\mathrm{I}}\right)$ is calculated using: $H^{\prime}=-\sum p_{\mathrm{i}} \ln \mathrm{p}_{\mathrm{i}}$; where; $\mathrm{H}^{\prime}=$ Shannon wiener; pi=proportion of each plant species in the sample plot, and $\ln =$ natural logarithm. Simpson index of dominance (ID); $\mathrm{D}=\sum \mathrm{p}_{\mathrm{i}}^{2}$; where: ID = Simpson index of dominance; $p_{i}=$ proportion of each plant species in the sample plots.

\section{Woody plant species evenness $(J)$ and Reciprocal $(R)$}

Woody plant species evenness $(\mathrm{J})$ was calculated through:

$J=\frac{H^{\prime}}{\log (s)}$

and the reciprocal $(\mathrm{R})$ was obtained from

$R=\frac{1}{I D}$ where $\mathrm{R}=$ Reciprocal $; 1=$ constant ID = Simpson index of dominance.

\section{RESULTS AND DISCUSSION}

\section{Woody Plant Species Diversity and Composition}

A total of 129 woody plant species were identified at MGBFR belonging to shrubs, lianas and trees, belonging to overall 38 families and 89 genera (Table 1). Of the 129 woody plants, 68 were trees (53\%), 49 were trees $(38 \%)$ and only 11 species (9\%) belonged to woody climbers (Figure 2). The diversity index is a mathematical measure of species diversity in a community. Diversity indices provide more information about community composition; they also take the relative abundances of different species into account (Kent and Coker, 1992). The plant diversity index measures a variety of plant taxa existing in a particular area. It may consider at family, genera or species diversity level (Leinster \& Cobbold, 2010).

Figure 2: Pie chart showing species diversity percentage per category

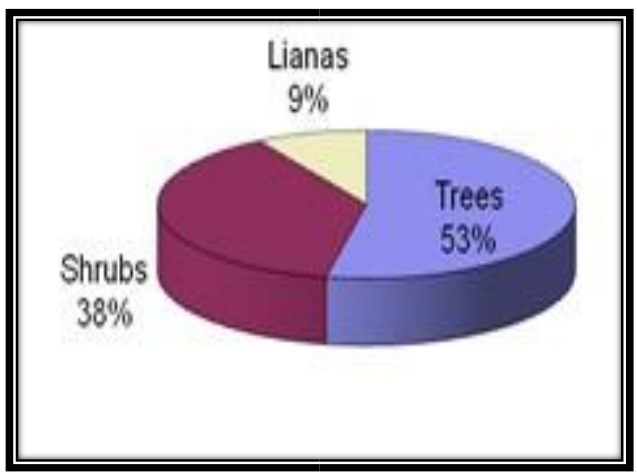


The number of stems of plants species forms usually varies among themselves. The MGBFR revealed to have the highest number of stems of shrubs per hectare, followed by trees and lianas were ranked the least (Table 1). The number of stems contributes to the computations of the diversity and dominance indices (Kent \& Coker, 1992; Giliba et al., 2011).

Table 1: Total number of woody plant species stems per hectare.

$\begin{array}{lllll}\begin{array}{l}\text { Unit } \\ \text { measure }\end{array} & \text { Tree } & \text { Shrubs } & \text { Liana } & \text { Total }\end{array}$

\begin{tabular}{lllll}
\hline $\begin{array}{l}\text { Per } \\
\text { hectare }\end{array}$ & 171 & 244 & 32 & 447 \\
\hline
\end{tabular}

\section{Woody Plant Species Index of Diversity $\left(\mathrm{H}^{\prime}\right)$ and Dominance (ID)}

The value of diversity index entails the level of plant species diversity to whether is high or low.
The index of diversity calculated was 4.271 (Table 2 ). This implied very high woody plant species diversity within such a relatively small area with only 600 hectares. The high woody plant species diversity implied moderate disturbance to the vegetation, a situation that could have stimulated the growth of more other woody plant species. The total protection of vegetation my lead into low species diversity as only the opportunistic plants will grow, while many others may fail to compete, and thus diminished diversity of plant taxa. The other scenario is that excessive disturbance to plant species such as charcoal, clearing for farms and overgrazing may lead to complete damage of plant species and finally desertification. In the case of MGBFR, the presence of a moderate disturbance in most of the areas has stimulated higher diversity, while in the southern part, where excessive damage from grazing and browsing was revealed, the woody plant species diversity is rather facing a high rate of decrease in number.

Table 2: Total families, genera, species and $\mathrm{H}^{\prime}$ for woody plant species of MGBFR in 36 plots

\begin{tabular}{lllll}
\hline Variable & Families & Genera & Species & H' $^{\prime}$ \\
\hline Value & 38 & 89 & 129 & 4.271 \\
\hline
\end{tabular}

Out of 129 woody plant species, only $17(13.2 \%)$ (Figure 3) woody plant species were ranked as the highest built on biodiversity and dominance indices, $15(11.6 \%)$ were medium (Figure 4) while the rest $97(75.2 \%)$ were termed as the least according to this research judgment. Those woody plant species diversity indices of 0.077 to 0.183 were treated as the most dominant.

\section{Most, Medium and Least Dominant Woody Plant Species}

Those with index of diversity of 0.076 to \pm 0.043 were judged as the medium dominant, while the rest with the index of dominance less than 0.043 were considered as the least dominant. The most dominant woody plants were 17 (Figure 3) and included Grewia forbesii, Euphorbia cuneata, Canthium burtii, Julbernardia globiflora, Cassipourea mollis, Margaritaria discoidea, Abrus schimperi, Stigmatorynchus melliferus, Commiphora coerulea, Tennantia senii, Dichrostachys cinerea, Terminalia sericea, Commiphora mossambicensis, Combretum apiculatum, Maerua triphylla, Grewia biclor, and Grewia similis (Figure 3). 
East African Journal of Environment and Natural Resources, Volume 2, Issue 1, 2020

Article DOI: https://doi.org/10.37284/eajenr.2.1.125

Figure 3: Most dominant woody plant species

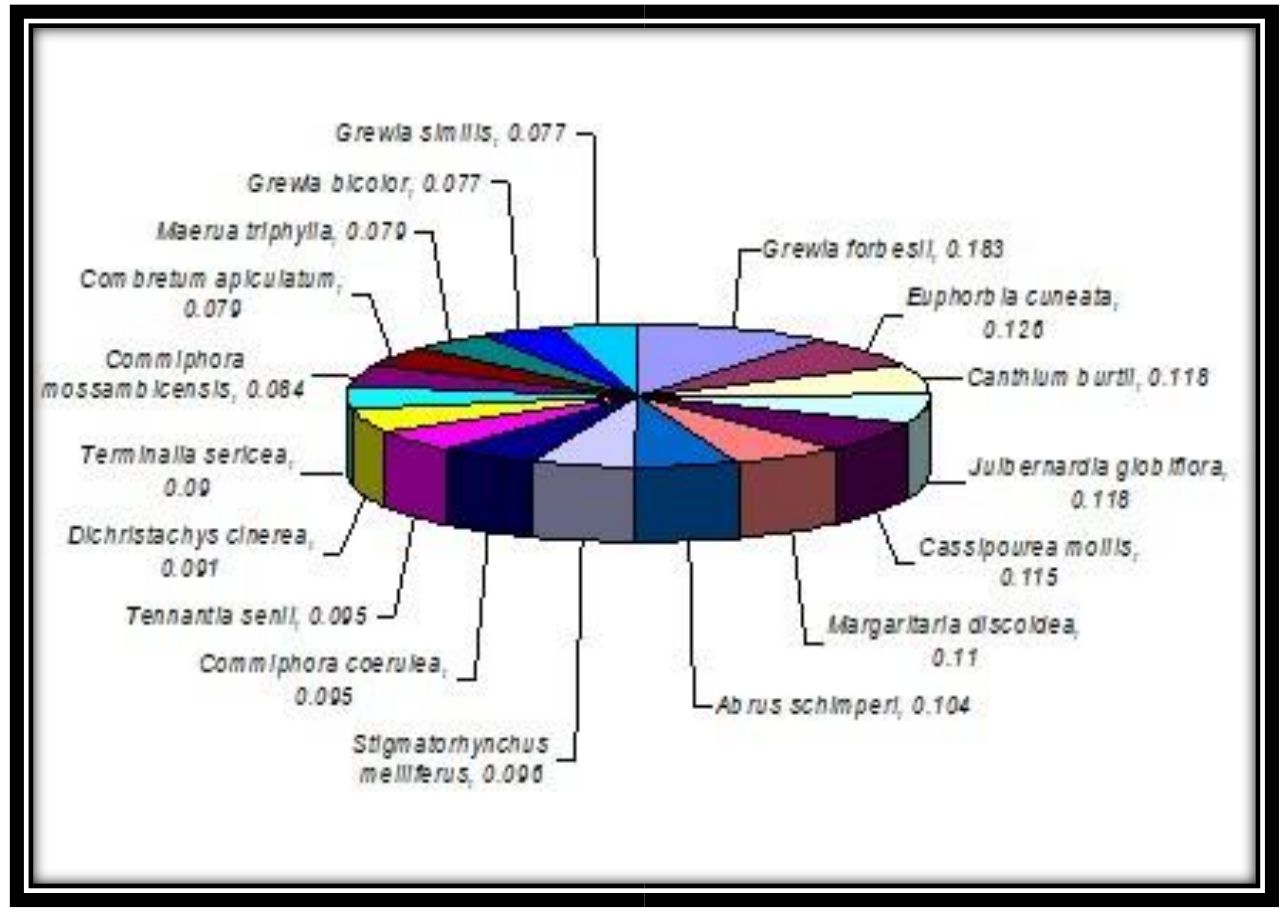

While the moderate dominant woody plant species were Schrebera trichoclada, Markhamia acuminata, Allophyllus africanus, Combretum collinum, Dalbergia arbutifolia, Steganotaenia araliacea, Vernonia amygdaliana, Ochna ovata,
Tapiphyllum velutinum, Tricalysia ovalifolia, Vitex strikeri, Vepris glomerata, Xeroderris stuhlmanii, Ximenia americana, Delonix elata and Zanthoxyllum chalybeum (Figure 4).

Figure 4: Pie chart showing the moderate dominant woody plant species.

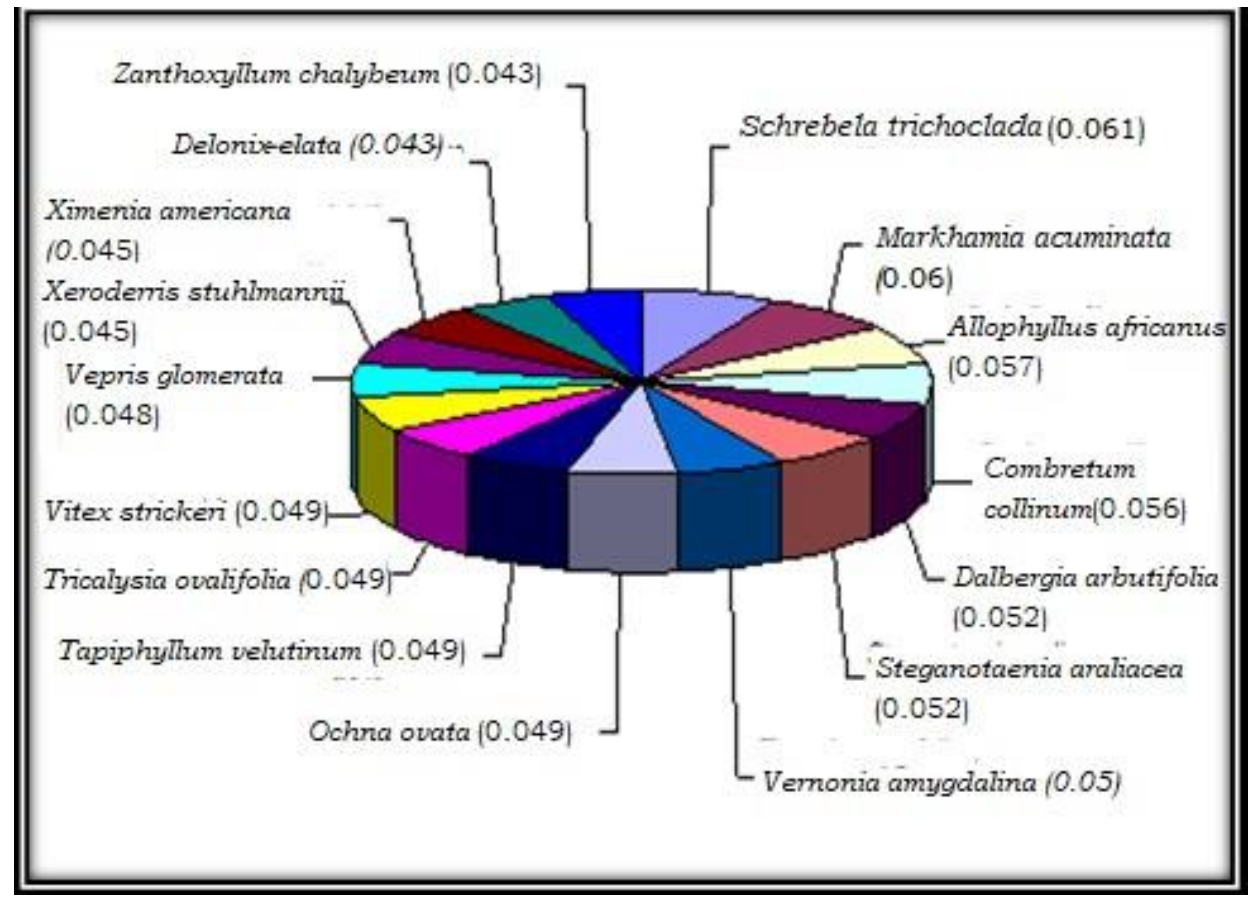




\section{Woody Plant Species Families}

Out of 38 families, only 8 of them were ranked as the medium and the most dominant grounded on the total number of species per family. Those with above 10 woody plant species were considered as the most dominant in terms of number of species. Those were: Rubiaceae (16) and Fabaceae (28), whereas those with 5 to 10 species were ranked as moderate and included; Lamiaceae (5),
Anacardiaceae (5), Combretaceae (8), Burseraceae (7), Capparaceae (8) and Euphorbiaceae (9). The rest of the families got only 1 to 3 species each and were ranked as the least dominant according to this research (Table 2). 85 woody plant species contributed to the most dominant families, and this was $66.7 \%$ of all 129 woody plant species identified at the surveyed site. The rest families with a total of 43 species $(33.59375 \%)$ were occupied the least number of species (Table 3).

Table 3: Total number of woody plant species per family percentage

\begin{tabular}{lll}
\hline Family name & Total no. of species & Percentage (\%) \\
\hline Fabaceae & 28 & 21.7 \\
Rubiaceae & 16 & 12.4 \\
Euphorbiaceae & 9 & 7 \\
Capparaceae & 8 & 6.2 \\
Burseraceae & 7 & 5.4 \\
Anacardiaceae & 5 & 3.9 \\
Combretaceae & 8 & 6.2 \\
Lamiaceae & 5 & 3.9 \\
Total most dominant families & 85 & 66.7 \\
The least dominant families & 44 & 33.3 \\
Overall total families & $\mathbf{1 2 9}$ & $\mathbf{1 0 0}$ \\
\hline
\end{tabular}

Woody Plant Species Evenness $(\mathrm{J})$ and Index of Dominance and Evenness

For evenly distributed taxa we would expect to get a value of 1 , but in this case, we have more than one, an implication of high variation in species occupancy. Most of the woody plant species got small dominance index (D), but contributed to the diversity for MGBFR, as each of them had occupied a portion in the locality even though were at such small coverage (Ratner, 2015). The larger the species occurrence for the most dominant woody plants the lower the diversity as few opportunistic higher plants will cover the area, while variation in species remains relatively low (Giliba et al., 2011). Simpson's index (D) gives a strong weighting to the dominants. It is also easily understood (Hill et al., 2002). The woody plant species that got the highest index of dominance also, got the highest diversity, the moderate also got moderate dominance index, whereas the least in terms of diversity index were equally ranked the least in terms of dominance index. This is because both the index of diversity and the dominance indices rely on the frequency, and that the higher the individual plant species frequency, the higher the index of diversity as well as the dominance index. The dominance, just like the diversity index is very useful as it entailed the species evenness and richness (Giliba et al., 2011).

\section{Dominance Index and Reciprocal as a Determinant of Diversity}

The calculated overall index of dominance of 0.02079 with a reciprocal of 48.1 implied high woody plant species diversity for MGBFR. As a rule, the lower the index of dominance in the scale of 0 and 1, the higher the diversity. Also, the close the value to 1 , the lower the species diversity and vice versa. But the lower the reciprocal, the lower the diversity while the higher the reciprocal entails higher the diversity (Kent and Coker, 1992). 


\section{Woody Plant Species Evenness (J) and Reciprocal (R)}

The woody plant species, with J of 2.0237 (revealed that they were not evenly distributed, as some of them were the most dominant, others were moderate and the rest were the leas dominant. The evenness (J) was 2.0237. On the other hand, the higher $\mathrm{R}$ (48.1) revealed high plant species diversity in MGFR. The plant species evenness is related to the richness (S) (Shirima et al., 2015).

\section{Central Tendency of Woody Plant Species}

The study findings came up with the highest mean stems belonging to the shrubs shadowed by trees, and lianas were the least (Table 4). Shrubs got the highest standard deviation (20.1), followed by lianas (17.8) and trees were the least in terms of standard deviation. This meant shrubs deviated most of all other woody plant forms. Lianas $(222.5 \%)$ fell under category with the highest dissimilarities of stems in the plots, whereas the trees $(38.1 \%)$ were ranked the second, while shrubs $(32.9 \%)$ were least varied among all others. The standard error for the woody plants showed that shrubs got the highest figure (3.35), followed by lianas (2.96) and trees (2.72).

Table 4: Central tendency of woody plant species

\begin{tabular}{llll}
\hline Variable & Tree & Shrub & Liana \\
\hline Mean & 42.83 & 60.92 & 8 \\
Standard deviation (STDV) & 16.3 & 20.1 & 17.8 \\
Coefficient of variation & 38.1 & 32.9 & 222.5 \\
Standard error & 2.72 & 3.35 & 2.96 \\
\hline
\end{tabular}

\section{CONCLUSION}

MGBFR patch accommodates relatively high woody plant species diversity. The woody plant species that occurred most in the research site were the most dominant and got the highest diversity and dominance indices. Woody plant species high diversity implied moderate anthropogenic disturbances that could have stimulated the regeneration of most woody plant species that could fail to grow under excessive competition from the most dominant woody plants, whereas excessive damage leads to massive loss of plant diversity and thus leading to desertification. There is a linear relationship between the increase in the independent variable and the dependent variable. Total protection may encourage high plant species diversity, but in long run it may lead to low diversity due to few species overwhelming the weaker ones. The families that got a larger number of plant species were also, considered as the dominant from that angle. The legal and illegal activities had an impact on woody plant diversity, whereas the illegal ones dominated due to continuous occurrence haphazardly such as charcoal making and overgrazing.

MGBFR is such a potential area in terms of biological diversity, hence recommendations area made that: ecotourism establishment as among environmentally friendly project; Determination of all plant species of MGBFR habits including herbs, sedges, grasses, lianas, trees and shrubs, education use campaigns by Dodoma city, encourage woodlot development at household level, awareness creation on safety and negative impacts generated from environmental damage, provision of environmental conservation education to include, enhance non-woody income generating projects, discourage settlement expansion into the remaining forest patch, funds should be made available through out to manage the forest patch, minimize political based emotion decisions, enhance alternative sources of energy to the local people. 


\section{ACKNOWLEDGEMENT}

Many thanks are due to the community of the University of Dodoma for their constructive material and moral support throughout my research carrier. Also, appreciation is extended to the former CDA Environmental Director (CDAED) for granting me permission to pursue my study at MGBFR. The MGFR Supervisor Mr. Joel Kilamiani and the local security guides provided useful guidance during data collection. The Tropical Pesticides Research Institute, particularly the head of the herbarium, Dr. E. Njau is acknowledged for allowing me to use the herbarium for identification of plant species collected from the study area. Missouri Botanical Garden (MBG) specifically Roy E. Gereau found funds to support this study during my MSc. Studies course work and fieldwork. Likewise, the faults and omissions in this study are solely mine and should not be attributed to any other person or institutions mentioned above.

\section{REFERENCES}

Agresti, A. and Finlay, B. (2008). Statistical Options for the Social Sciences, $4^{\text {th }}$ Edition. Upper Saddle River, NJ: Prentice Hall.

Baldus, R. and Siege, L. (2003). The selous-Nissa wildlife corridor, Tanzania wildlife. Discussion paper No. 34, Dar-es-salaam.

Bein, E., Habte, B., Jaber, A., Birnie, A. \& Tengnas, B.O. (1996). Useful trees and shrubs in Eritrea. Identification, propagation and management for agricultural and pastoral communities. Technical handbook No. 12. Regional soil conservation Unit, Nairobi.

Evangelista A, Frate L, Carranza ML, Attorre F, Pelino G, stanisci A. (2016). Changes in composition, Ecology and structure of highmountain vegetation: a re-visitation study over 42 years. AoB PLANTS, 8, 1-12.

Geldenhuys, K. J. (2013). The many uses of Pterocarpus angolensis. Department of Forest $\&$ Wood Science, University of Stellenbosch.

Giliba R A, Boon E K, Kayombo CJ, Musamba EB, Kashindye AM and Shayo PF (2011). Species composition, Richness and Diversity in Miombo Woodland of Bereku Forest Reserve, Tanzania. J. Biod, 2(1), 2-7.

Kent, M. and Coker, P. (1992). Vegetation Description and Analysis. A practical approach. Belhaven Press. Floral Street, London.

Kupnick, G. (2001). Role of plant diversity. Centre for diversity of America. National Museum of Natural History.

Leinster, T. and Cobbold, C.A. (2010). Measuring diversity: the importance of species Similarity ISchool of Mathematics and Statistics. Glasgow, UK. Boyd Orr Centre for Population and Ecosystem Health, University of Glasgow.

Malimbwi, R. E., Mugasha, A. G. \& Monela, G.C. (2005). Reconnaissance Timber Inventory Report for Handeni Hill Forest Reserve in Handeni District, Tanzania. Morogoro, Tanzania: Faculty of Forestry and Nature Conservation, Sokoine University of Agriculture.

Malmer, A and Gert Nyberg, G. (2008). Forest and water relations in miombo woodlands: Need for understanding of complex stand management. Working Papers of the Finnish Forest Research Institute 98: 70-86. Research and development for sustainable management of semiarid miombo woodlands in East Africa. Umeå, Sweden: Swedish University of Agricultural Sciences.

Missanjo, E., Ndalama, E., Sikelo, D. and Kamanga. (2015). Quarry dust emission effects on tree species diversity in Chongoni forest reserve and vegetation characteristics in adjacent villages, Dedza, Malawi. International Journal of Information Research and Review, 2(3), 511-515.

Moore, R., Clark, W. D., Stern, K. R. \& Vodopich, D. (1995): An introduction to botany. WM.C. Publishers. Brown Communication. United States of America.

Mugasha, W. A., Mwakalukwa, E. E., Luoga, E., Malimbwi, R. E., Zahabu, E., Silayo, D. S., ... 
\& Kashindye, A. (2016). Allometric models for estimating tree volume and aboveground biomass in lowland forests of Tanzania. International Journal of Forestry Research, 2016.

Naughton, L. (2007). Collaborative land use planning: zoning for conservation and development in protected areas. Land Tenure Centre No. 4. Land Tenure Centre.

Owen-Smith, N. \& Cooper, S. M. (1987). Palatability of Woody Plants to Browsing Ruminants in a South African Savanna. Ecology Journal, 68, 319-331.

Polhill, D. (1988): Flora of Tropical East Africa Index of collecting localities. Regional Botanical Gardens. In Kew. Robertson, S.A. (1989). Flowering plants of Seychelles. An annotated checklist of Angiosperms and Gymnosperms. The Royal Botanic Gardens Kew.

Primack, R.B. (2002). Essentials of conservation biology. Third edition. Sunderland, Massachusetts.

Ruffo, C. K. (2002). Edible wild plants of Tanzania. Nairobi: Regional Management Unit (RELMA).

Sapieha, T. (2008). Wayside Flowers of East Africa. Nairobi, KE: itho Printers.

Sarma, K. V. S. (2006). Statistics made simple. Do it yourself on PC. Tirupati, New Dehl: Department of Statistics, Sri lank Venkateswara University.

Shirima, D., Totland, O., Munish, P., and Moe S. (2015). Relationships between tree species richness, Evenness and aboveground carbon storage in montane forests and miombo woodlands of Tanzania. Basic and Appl. Ecol, 16(3), 239-249.

Stohlgren T, Falkener M, Schell L. (1995). A Modified Whittaker Nested vegetation sampling Method. Plant Ecol, 117(2), 113 121.
Temu, R. P. and Nsolomo, V. R. (2000). List of Uluguru Mountains endemic vascular plants. The Uluguru mountains biodiversity conservation project. Morogoro, TZ: Department of Forest Biology, Sokoine University of Agriculture.

Thijs, K. W., Roelen, I. and Musila, W. M. (2014). Field Guide to the Woody Plants of Taita, Kenya.

Tunholi, V. P., Ramos, M. A. \& Scariot, A. (2013). Availability and use of woody plants in a agrarian reform settlement in the cerrado of the state of Goiás, Brazil. Acta Botanica Brasilica, 27(3),

$604-$ 612. https://doi.org/10.1590/S010233062013000300018

UNEP. (2007): United Nations Environmental Programme Annual Report. Nairobi, Kenya: United Nations Environmental Programme.

United Republic of Tanzania. (2007). Community Based Forest Management Guidelines for the Establishment of Village Land Forest Reserve and Community Forest Reserves. Ministry on Natural Resources and Tourism, Forestry and Beekeeping Division.

United Republic of Tanzania. (2002). The Forest Act No. 14 of 2002. Ministry of Natural Resources and Tourism, Dar-es-salaam, Tanzania.

United Republic of Tanzania. (2014): Location and Climate of Dodoma Municipality. Dodoma Capital Development Authority.

United Republic of Tanzania. (2007). The Green Belt of Dodoma, Tanzania.

United Republic of Tanzania. (2004). National Beekeeping Programme. People and Bees. A plain language guide to the United Republic of Tanzania.URT. (2002): National sample census of agriculture. Volume VIII-a: Regional Report-Dodoma.

United Republic of Tanzania. (1976). Dodoma Capital Development Authority progress Report, Tanzania. 
East African Journal of Environment and Natural Resources, Volume 2, Issue 1, 2020

Article DOI: https://doi.org/10.37284/eajenr.2.1.125

Wiegand, T., Huth, A., Getzin, S., Wang, X., Hao, Z., Gunatilleke, C. S., \& Gunatilleke, I. N. (2012). Testing the independent species' arrangement assertion made by theories of stochastic geometry of

biodiversity. Proceedings of the Royal Society B: Biological Sciences, 279(1741), 3312-3320. 